\title{
Níveis de proteína digestível para surubim (Pseudoplatystoma sp.) criados em tanque-rede
}

\section{Levels of digestible protein to surubim (Pseudoplatystoma sp.) reared in net cages}

\author{
Claucia Aparecida Honorato ${ }^{1 *}$; Thiago Tetsuo Ushizima ${ }^{2}$; \\ Carolina Isabel Flores Quintana ${ }^{3}$; Cristiane Meldau de Campos ${ }^{4}$; \\ Vanessa Menegatti Marcondes ${ }^{1}$; Camila Aparecida Nascimento ${ }^{1}$; \\ Fábio Mazzotti Santamaria ${ }^{2}$
}

\begin{abstract}
Resumo
O surubim (Pseudoplatystoma sp.) é uma das espécie de peixe carnívora que exige atenção especial na dieta ofertada. Este trabalho teve o objetivo determinar a exigência de proteína digestível de juvenis de surubim (Pseudoplatystoma sp.) criados em tanque-rede. $\mathrm{O}$ ensaio foi constituído por quatro dietas isoenergéticas $(2606,69 \pm 39,16 \mathrm{kcal} . \mathrm{kg}-1$ de energia digestível) contendo níveis crescentes de proteína digestível $(23,24,26$ e $28 \%$ PD) fornecidas aos juvenis de surubim $(157,35 \pm 11,23 \mathrm{~g})$ durante cinco meses. Os parâmetros de crescimentos, composição do filé, enzimas metabólicas hepáticas e morfometria do intestino e fígado foram analisados em delineamento inteiramente casualizado com quatro tratamentos e quatro repetições. $\mathrm{O}$ aumento de proteína na dieta proporcionou melhor ganho em peso. As enzimas do metabolismo hepático aumentaram nos peixes alimentados com 24\%PD. Não foram observadas alterações histopatológicas no fígado dos peixes. A histologia do intestino revelou adaptação ao aumento de proteína na dieta até o nível de $26 \%$ PD. Os juvenis de surubim mostraram-se exigentes em proteína digestível, apresentando os melhores resultados de desempenho de produção e de eficiência de utilização dos nutrientes com a dieta contendo $28 \%$ de PD.

Palavras-chave: Espécie neotropical, fontes protéicas, nutrição de peixes, peixes carnívoros
\end{abstract}

\begin{abstract}
The Pseudoplatystoma sp. is species of carnivorous fish that require special attention in the diet offered. This work had the objective to determine the digestible protein requirement of juvenile the Pseudoplatystoma sp. reared in net cages. The test consisted of four isoenergetic diets $(2606.69 \pm$ $39.16 \mathrm{kcal} \mathrm{kg-1}$ of digestible energy) containing increasing levels of digestible protein $(23,24,26$ and $28 \% \mathrm{PD})$ provided to juveniles of surubim $(157.35 \pm 11.23 \mathrm{~g})$ for five months. The parameters of growth, fillet composition, metabolic liver enzymes and morphometry of the intestine and liver were
\end{abstract}

\footnotetext{
${ }^{1}$ Prof ${ }^{\text {as }}$, Centro Universitário da Grande Dourados, UNIGRAN, Faculdade de Ciências Biológicas e da Saúde, Medicina Veterinária, Dourados, MS. E-mail: clauciahonorato@yahoo.com.br; vanessamenegattimarcondes@yahoo.com.br; camila.nascimento05@, gmail.com

${ }^{2}$ Gerentes de Pesquisas, Mar \& Terra S.A., Itaporã, MS. E-mail: thiago@mareterra.com.br; santamarí@@mareterra.com.br

${ }^{3}$ Prof ${ }^{a}$, Ictiología del Nordeste, Facultad de Ciencias Veterinarias, Universidad Nacional del Nordeste-Corrientes, Corrientes, Argentina. E-mail: carolina@vet.unne.edu.ar

${ }^{4}$ Prof ${ }^{a}$, Universidade Estadual do Mato Grosso do Sul, Unidade Universitária de Aquidauana, UEMS, Aquidauana, MS. E-mail: cmeldau@uems.br

* Autor para correspondência
} 
analyzed in completely randomized design with four treatments and four replicates. An increase of protein in the diet provided better weight gain. The metabolic liver enzymes increased in fish fed 24PD. The histopathological changes were not observed in the liver of the fish. The bowel histology showed adaptation to increased protein in the diet until the 26 level PD. juveniles of Pseudoplatystoma sp. were demanding in digestible protein, showing the best results of production performance and nutrient use efficiency with the diet containing $28 \%$ PD.

Key words: Neotropical species, protein sources, fish nutrition, carnivorous fish

\section{Introdução}

Devido a necessidade de se incrementar a produtividade nos sistemas aqüícolas, a crescente demanda por pescado tem gerado grande interesse pelo cultivo de peixes (RESENDE et al., 2007) e o uso de tanques-rede é bastante difundido, mundialmente para produção de peixes em regime de criação intensiva na escala industrial (SAMPAIO et al., 2013) e é excelente alternativa para o aproveitamento racional de corpos hídricos que apresentam dificuldades para a prática da piscicultura convencional.

Este sistema de produção possui várias vantagens, entre elas o baixo custo de implantação e a exigência de infra-estrutura. No Brasil a criação em tanques-rede se expandiu de forma expressiva devido a utilização de altas densidades de peixes por unidade de área ou volume; início da oferta de rações completas e a utilização de tanques ou gaiolas de diferentes formas e dimensões, durante o processo de recria e engorda (ONO, 2005; AYROZA et al., 2011). O uso de tanque-rede para criação de peixes em escala industrial é economicamente viável (SAMPAIO et al., 2013) para espécies como tilápia do Nilo, Oreochromis niloticus (AYROZA et al., 2011), pacu, Piaractus mesopotamicus, tambaqui, Colossoma macropomun (ONO, 2005) e surubim, Pseudoplatystoma corruscans (LIRANÇO; ROMAGOSA; SCORVO-FILHO, 2011).

Liranço, Romagosa e Scorvo-Filho, (2011) comparando sistema de produção para o surubim, verificaram que o desempenho dos peixes em tanque-rede foi inferior aos peixes cultivados em tanques escavados. No sistema intensivo a densidade de estocagem por área é elevada (AYROZA et al.,
2011) exigindo dietas que atendam as necessidades nutricionais de mantença e crescimento da espécie.

Dentre os entraves da nutrição de organismos aquáticos está a relação proteína e energia das dietas para peixes carnívoros (BOOTH et al., 2013). A possibilidade de substituição de fração da proteína da dieta, por menor que seja, pode representar, em produção de larga escala, não só um efetivo ganho financeiro, mas um impacto ambiental significativamente menor (JIRSA et al., 2013; MARTINO et al., 2002). Como o catabolismo oxidativo das proteínas é nutricional e economicamente pouco eficiente, a ação poupadora da proteína por fontes de energia como o carboidrato tem sido estudada (HONORATO et al., 2010).

Ressalta-se que em espécies carnívoras, a utilização e a digestibilidade de carboidratos como fonte de energia é aparentemente limitada (ALMEIDA FILHO et al., 2012). Del Carratore (2001) constatou para o surubim que a inclusão de amido cru deve ser de $16 \%$, devido as dificuldade de digestão e de absorção de alimentos complexos como polissacarídeos. Lundstedt, Melo e Moraes (2004) apontaram que o nível de carboidrato para o surubim está entre 13 e $25 \%$, sendo possível a utilização de até $25 \%$ de carboidrato.

Muitos estudos realizados para determinar a exigência de proteína para espécies de peixes podem estar superestimado por não considerar a digestibilidade dos ingredientes (GONÇALVES; CARNEIRO, 2003) e consequentemente inviabilizam o resultado de desempenho produtivo. O nível de proteína da dieta deve estar estreitamente relacionado aos ingredientes empregados, de acordo com sua inclusão e valor 
nutricional de seus aminoácidos, assim como do balanceamento da energia e dos demais nutrientes da ração (ALMEIDA FILHO et al., 2012).

O objetivo deste trabalho é determinar a exigência de proteína digestível de juvenis de surubim (Pseudoplatystoma sp.) criados em tanque rede.

\section{Material e Métodos}

Esse trabalho foi desenvolvido na unidade de produção de surubins no município de Angelica (Latitude: $22^{\circ} 09^{\prime} 12^{\prime \prime} \mathrm{S}$ e Longitude: $53^{\circ} 46^{\prime} 16^{\prime \prime}$ W), distrito de Ipezal - MS propriedade parceira da empresa Mar \& Terra Ltda, de Itaporã-MS, que forneceu os alevinos de surubim (Pseudoplatystoma sp.) para a realização da pesquisa. Ao chegarà unidade de produção os alevinos foram acondicionados em tanque-rede onde receberam dieta comercial até o peso de 157,35 $\pm 11,23 \mathrm{~g}$. Posteriormente foram distribuídos em 20 tanques de $4,8 \mathrm{~m}^{3}(2 \times 2 \times 1,2)$ com abertura de malha de $20 \mathrm{~mm}$, com 70 peixes por tanque, onde permaneceram durante o período de agosto de 2011 a janeiro de 2012.

A qualidade de água foi monitorada mensalmente com o multiparâmetro HANNA modelo HI92982813, para aferição de: temperatura, oxigênio dissolvido, potencial hidrogeniônico ( $\mathrm{pH})$, condutividade elétrica, salinidade, alcalinidade. A temperatura foi aferida diariamente antes da alimentação para realizar as estimativas de controle de arraçoamento.

Foram utilizadas quatro dietas extrusadas comerciais (Douramix Ltda -Dourados/MS) com os níveis de proteína digestível $(23,24$, 26 e 27\%) substituindo gradativamente por carboidratos (CHO) compondo dietas isocalóricas de 2606,69 $\pm 39,16$ ED.kcal $^{-1}$ (Tabela 1). Nas dietas as fontes de proteínas utilizadas foram à farinha de peixe e farelo de soja, amido gelatinizado como fonte de carboidrato e óleo de soja como fonte de lipídio e apresentavam mistura vitamínico-míneral, vitamina $\mathrm{C}$ protegida, betaína, e caulin.

Tabela 1. Composição bromatológica analisada das dietas com níveis crescentes de proteína digestível para alimentação de surubim.

\begin{tabular}{lcccc}
\hline \multirow{2}{*}{ Composição } & \multicolumn{4}{c}{ Níveis de proteína digestível (\%) } \\
\cline { 2 - 5 } & $\mathbf{2 3}$ & $\mathbf{2 4}$ & $\mathbf{2 6}$ & $\mathbf{2 7}$ \\
\hline Matéria Seca & 92,97 & 92,3 & 91,85 & 92,85 \\
Proteína bruta & 34,3 & 35,77 & 38,14 & 39,39 \\
Proteína digestível * & 23,77 & 24,99 & 26,21 & 27,44 \\
Lipídeos & 8,02 & 7,72 & 8,75 & 9,72 \\
Extrativo não nitrogenado & 37,1 & 36,97 & 32,19 & 30,48 \\
Fibra bruta & 2,52 & 2,4 & 2,34 & 2,02 \\
Matéria mineral & 11,03 & 9,44 & 10,43 & 11,24 \\
Cálcio & 3,42 & 3,03 & 3,14 & 3,61 \\
Fósforo & 1,8 & 1,71 & 1,81 & 1,88 \\
Energia bruta & 4319,8 & 4343,8 & 4244,5 & 4279,2 \\
Energia digestível * & 2648,86 & 2623,86 & 2596,62 & 2557,42 \\
\hline
\end{tabular}

* Proteína e energia digestível calculada com base nos percentuais de digestibilidade dos ingredientes para o surubim (Pseudoplatystoma corruscans) de Gonçalves e Carneiro (2003). Composição analisada das dietas segundo AOAC (2000).

Fonte: Elaboração dos autores.

A cada 30 dias foram realizadas biometrias de desempenho produtivo: Ganho em peso $(\mathrm{GP})=$ intermediárias, em 10\% dos peixes para analise (peso final - peso inicial), consumo de dieta (CD) 
= consumo médio de alimento / tempo, conversão alimentar $(\mathrm{CA})$ = consumo de alimento / ganho em peso total, taxa de crescimento específico $(\mathrm{TCE})=$ (ln peso final - $\ln$ peso inicial) x $100 /$ tempo, taxa de eficiência protéica $($ TEP) $=$ ganho em peso vivo / proteína bruta consumida. Ao final do período experimental foi realizada a contagem de todos os exemplares para o calculo de sobrevivência.

Ao final do ensaio dez peixes de cada tratamento foram anestesiados com benzocaína (100mg. $\mathrm{L}^{-1} \mathrm{de}$ água) e sacrificados por transecção medular. Estes foram abertos e coletados fragmentos de intestino e fígado. O fígado dos peixes foi retirado e pesado para o calculo do índice hepatossomático (IHS) = peso do órgão/peso do animal.

Os peixes foram filetados e os músculos foram triturados e secados em estufa a $65^{\circ} \mathrm{C}$ até peso constante e moídos para obtenção de material para realização das análises de umidade, proteína bruta, extrato etério (AOAC, 2000).

Amostras de fígado de 100mg foram homogenizadas com tampão fosfato de sódio (glicerol v/v em tampão fosfato de sódio $20 \mathrm{mM}$ e Tris $10 \mathrm{mM}-\mathrm{pH} 7,0$ ) em homogenizador tipo Potter-Elvehjem. Posteriormente, esta amostra foi centrifugada a $4^{\circ} \mathrm{C}$ por três minutos a $600 \times \mathrm{g}$ e o sobrenadante submetido a uma nova centrifugação por oito minutos a 6000 x $g$. O sobrenadante foi utilizado para as analises enzimáticas da alanina aminotransferase (ALAT) e aspartato aminotransferase (ASAT). As mensurações da atividade da ALAT e ASAT foram determinadas pelo método de Reitman e Frankel (1957). As leituras das amostras foram realizadas por espectrofotometria (espectrofotômetro semi-automático Bioplus S-200), com luz de comprimento de onda apropriado para cada teste.

Para análise histológica fragmentos de fígado e intestino foram fixados em solução formalina tamponada a $10 \%$ por 24 horas e depois lavados em álcool $70 \%$ até o processamento. Após a fixação, foram desidratados, diafanizados e incluídos em parafina com polímero plástico Histosec (Merck). A seguir, foi realizado a microtomia para obtenção de cortes de 2 a $5 \mu \mathrm{m}$ de espessura, que foram corados com Hematoxilina-Eosina para realização da histomorfometria, e realizado o método histoquímico de PAS-H para observação das células de secreção. As análises microscópicas e a histomorfometria e a documentação do material foram realizadas em fotomicroscópio Olympus BX41. Para a morfometria do material foram selecionadas duas lâminas por tratamento na qual foram fotografadas sete secções. Posteriormente foram mensurados o diâmetro dos hepatócitos e diâmetro do núcleo dos hepatócitos e calculada a relação hepatócito e núcleo. No intestino anterior foi mensurada a altura da vilosidade. As análises foram realizadas no Instituto de Ictiologia da Facultad de Ciencias Veterinarias na Universidad Nacional del Nordeste - Corrientes - Argentina.

$\mathrm{O}$ delineamento experimental foi inteiramente casualisado (DIC) com quatro tratamentos e quatro repetições. As médias foram submetidas à análise de variância (ANOVA) e, apresentando significância, realizou-se a comparação das mesmas pelo teste Tukey.

\section{Resultados e Discussão}

O desempenho de produção dos juvenis de surubim é susceptível as variações de proteína digestível ofertada (Tabela 2). A sobrevivência foi elevada para todos os tratamentos, com taxas acima de 91\%. Os valores de ganho em peso aumentaram linearmente em função do aumento da proteína digestível na dieta $(\mathrm{P}<0,05)$, obtendose o maior valor com os peixes alimentados com a dieta contendo $27 \%$ PD. No entanto, os demais parâmetros (consumo de dieta, conversão alimentar, taxa de crescimento específico e taxa de eficiência protéica) não foram significativamente afetados pelo aumento da PD na dieta. A alta exigência de proteína para as fases iniciais de crescimento já foi reportado (LUNDSTEDT, 2004) enquanto que para 
fases finais de crescimento não é conhecido se esta espécie ainda necessita de altos níveis de proteína para seu desenvolvimento. Para alevinos de surubim a exigência de proteína é elevadas sendo as maiores respostas de crescimento obtidas com a dieta contendo 32\% proteína digestível (GONÇALVES, 2002). Zanardir, Boquembuzo e Koberstein (2008) observaram em juvenis de surubim a exigência de $40 \%$ PB e energia bruta de $3781 \mathrm{Kcal} / \mathrm{Kg}$. No presente trabalho observou-se que a dieta com
$27 \% \mathrm{PD}$ foi a que apresentou melhor ganho em peso (Tabela 2), observa-se que está possui o menor nível de carboidrato $(30,48 \%)$. A alta exigência de proteína para espécies carnívoras deve-se a baixa capacidade de utilização de carboidratos (DEL CARRATORE, 2001) e lipídeos (JIRSA et al., 2013) para fins energéticos. Em peixes, particularmente as espécies carnívoras, a utilização e a digestibilidade de carboidratos como fonte de energia é aparentemente limitada (BOOTH et al., 2013).

Tabela 2. Valores de F, coeficiente de variação $(\mathrm{CV})$ e desempenho de surubins alimentados com dietas de níveis crescentes de proteína digestível.

\begin{tabular}{|c|c|c|c|c|c|c|}
\hline \multirow{2}{*}{ Parâmetros } & \multicolumn{4}{|c|}{ Proteína Digestível (\%) } & \multirow{2}{*}{$\mathbf{F}$} & \multirow{2}{*}{$\mathbf{C V}$} \\
\hline & 23 & 24 & 26 & 27 & & \\
\hline Ganho em peso (g) & $361,92 \pm 24,58 \mathrm{~B}$ & $363,64 \pm 27,98 \mathrm{~B}$ & $373,61 \pm 23,58 \mathrm{~B}$ & $400,35 \pm 18,37 \mathrm{~A}$ & $30,30^{*}$ & 23,62 \\
\hline Consumo de dieta (g) & $502,67 \pm 93,57$ & $548,75 \pm 101,83$ & $535,75 \pm 114,60$ & $585,37 \pm 99,25$ & $9,60^{n s}$ & 101,75 \\
\hline Conversão Alimentar & $1,38 \pm 0,09$ & $1,52 \pm 0,28$ & $1,43 \pm 0,13$ & $1,49 \pm 0,38$ & $11,53^{n s}$ & 0,22 \\
\hline $\begin{array}{l}\text { Taxa de crescimento } \\
\text { específico }\end{array}$ & $0,62 \pm 0,07$ & $0,50 \pm 0,09$ & $0,59 \pm 0,09$ & $0,65 \pm 0,04$ & $5,49^{n s}$ & 0,07 \\
\hline $\begin{array}{l}\text { Taxa de eficiência } \\
\text { protéica }\end{array}$ & $2,13 \pm 0,12$ & $1,88 \pm 0,43$ & $1,85 \pm 0,15$ & $1,77 \pm 0,54$ & $14,43^{n s}$ & 0,31 \\
\hline Sobrevivência & $98,6 \pm 1,89$ & $91,7 \pm 7,13$ & $96,7 \pm 2,78$ & $98,3 \pm 1,35$ & $2,69^{n s}$ & 4,14 \\
\hline $\begin{array}{l}\text { Índice } \\
\text { hepatossomático }\end{array}$ & $1,4 \pm 0,1 \mathrm{~B}$ & $1,3 \pm 0,08 \mathrm{~B}$ & $1,8 \pm 0,07 \mathrm{~A}$ & $1,8 \pm 0,28 \mathrm{~A}$ & $27,63 * *$ & 6,02 \\
\hline
\end{tabular}

Médias seguidas de letras distintas reportam diferença estatística pelo teste de tukey $(\mathrm{P}<0,05)$. ns - não significativo, **(P $<0,01)$; $*(\mathrm{P}<0,05)$.

Fonte: Elaboração dos autores.

O efeito poupador de proteína por carboidrato depende da habilidade da espécie em digerir e aproveitar esta fonte de energia. Neste contexto de utilização de energia não protéica Del Carratore (2001) determinou que a inclusão de amido cru para o surubim deve ser de no máximo $16 \%$, atribuindo isso ao fato de ser uma espécie carnívora com dificuldade de digestão e de absorção de alimentos complexos como polissacarídeos. Por outro lado Lundstedt, Melo e Moraes (2004) demonstraram que o nível de carboidrato para o surubim está entre 13 e $25 \%$, sendo esta quantidade notáveis em carboidratos para uma espécie carnívora. Porém é consenso entre os autores que a qualidade do nutriente utilizado é o balizador para as resposta de desempenho. Para juvenis de surubim neste estudo os níveis de carboidratos das dietas variaram de 37,1 a $30,48 \%$, considerando a baixa habilidade desta espécie em digerir carboidratos a utilização de dietas extrusadas foi crucial para boas respostas de crescimento.

A baixa quantidade de carboidratos na dieta faz com que os peixes utilizem proteína para fins energéticos (BOOTH et al., 2013) e proporciona, ainda, aumento na excreção de amônia para o meio (LUNDSTEDT; MELO; MORAES, 2004) produzindo efluente com maior potencial poluente. 
O consumo de dieta foi satisfatório resultando em índices promissores de conversão alimentar. Cabe destacar que as dietas utilizadas demonstraram resultados positivos para o sistema de produção em tanque-rede independente do nível de proteína digestível utilizada. A conversão alimentar foi considerada satisfatória para todos os níveis de proteína digestível para surubins criados em tanque-rede. Liranço, Romagosa e Scorvo-Filho, (2011) observaram para a mesma espécie conversão alimentar de 2,37. Também, Zanardi, Boquembuzo e Koberstein (2008) trabalhando com juvenis de pintado com peso de $13 \mathrm{~g}$, observaram valores de conversão alimentar entre 2,37 e 3,94, valores superiores aos observados neste trabalho.

$\mathrm{O}$ índice hepatossomático aumentou nos peixes alimentados com as dietas de maior nível protéico (26 e 27\%PD). Cyrino, Portz e Martino (2000) estudando nível de proteína bruta para Black bass (Micropterus salmoides) observou aumento do índice hepatossomático para peixes alimentados com dietas de maior teor protéico. O fígado é um órgão que pode aumentar o tamanho e o peso em decorrência de sobrecarga metabólica pela degradação de proteína para fins energético (ALMEIDA et al., 2011). Alguns alimentos energéticos apresentam características favoráveis para substituir proteína, fato este demonstrado por Bicudo et al. (2012) que verificou para Pseudoplatystoma fasciatum que o índice hepatossomático não sofreu mudanças com a inclusão de farelo de glúten de milho na dieta.

Os níveis de proteína digestível nas dietas não alteraram características de umidade, matéria seca e proteína do file de surubim (Tabela 3) corroborando com Burkert et al. (2008) quando avaliaram filés de surubim cultivados em tanque-redes arraçoados com dietas de níveis crescentes de proteína e não observaram mudanças na composição bromatológica do filé. Matino et al. (2005) também não observaram mudança na composição corporal da carcaça de surubim quando alimentados com dietas com diferentes proporções entre carboidratos e lipídeos. No entanto, neste estudo o aumento de proteína digestível na dieta $(27 \%)$ para o surubim resultou em aumento no extrato etéreo do filé semelhantemente Cyrino, Portz e Martino (2000) observaram em Micropterus salmoides que a administração de dietas contendo níveis de proteína próximos a $42 \%$ condicionam um maior acúmulo de reservas energéticas. Bicudo et al. (2012) relatam que a eficiência da utilização de nutrientes é controversa devido a dinâmica de utilização de proteína e o metabolismo energético.

Tabela 3. Composição do filé de surubins alimentados com dietas de níveis crescentes de proteína digestível.

\begin{tabular}{|c|c|c|c|c|c|c|}
\hline \multirow{2}{*}{ Parâmetros } & \multicolumn{4}{|c|}{ Proteína Digestível (\%) } & \multirow{2}{*}{$F$} & \multirow{2}{*}{$C V$} \\
\hline & 23 & 24 & 26 & 27 & & \\
\hline Matéria seca & $36,56 \pm 3,23$ & $39,14 \pm 2,39$ & $42,80 \pm 5,04$ & $45,48 \pm 4,23$ & $3,12^{n s}$ & 9,41 \\
\hline Umidade & $63,44 \pm 3,23$ & $60,89 \pm 2,39$ & $57,20 \pm 5,04$ & $54,52 \pm 4,23$ & $3,15^{n s}$ & 6,54 \\
\hline Proteína bruta & $52,16 \pm 7,02$ & $41,17 \pm 7,54$ & $47,7 \pm 3,19$ & $44,42 \pm 1,56$ & $2,23^{n s}$ & 11,74 \\
\hline Extrato etéreo & $9,95 \pm 0,54 \mathrm{AB}$ & $9,73 \pm 0,44 \mathrm{AB}$ & $8,66 \pm 0,45 \mathrm{~B}$ & $10,98 \pm 0,93 \mathrm{~A}$ & $9,63 * *$ & 6,17 \\
\hline
\end{tabular}

Médias seguidas de letras distintas reportam diferença estatística pelo teste de tukey $(\mathrm{P}<0,05)$. ns - não significativo, $* *(\mathrm{P}<0,01)$; $*(\mathrm{P}<0,05)$.

Fonte: Elaboração dos autores.

Com o aumento de proteína digestível na aspartato aminotransferase (AST) responsáveis por alimentação dos surubins houve aumento nas degradação protéica (Figura 1A, B). O aumento da enzimas alanina aminotransferase (ALT) e relação proteína/carboidrato resulta em aumento da 
atividade da ALT e AST no jundiá R. quelen (MELO et al., 2006). Sánchez-Muros et al. (1998) associaram a alta atividade da glutamato desidrogenase e da ALT ao aumento da neoglicogênese. Em um estudo com níveis de proteína para juvenis de surubim também foi observado aumento da degradação protéica para fins energéticos conforme o aumento de proteína da dieta (LUNDSTEDT; MELO; MORAES, 2004). Metón et al. (1999) observaram aumento na atividade da ALAT hepática quando alimentaram $S$. aurata com altos níveis de proteína. Os autores sugerem que esta adaptação poderia denotar uma eficiente utilização dos aminoácidos da dieta tanto para crescimento como nos processos de gliconeogênese. Nesse estudo, as atividades das enzimas envolvidas no metabolismo de proteína foram responsivas ao aumento de proteína digestível, o qual estaria sendo usado como recurso energético aumentando a neoglicogênese a partir de aminoácidos.

Figura 1. Atividade enzimática da (ALT) Alanina aminotransferase (A) e (AST) aspartato aminotransferase (B) do fígado de surubins submetidos a dietas com níveis crescentes de proteína digestível. Letras distintas reportam diferença estatística pelo teste de Tukey ( $\mathrm{p}>0,05)$.

A

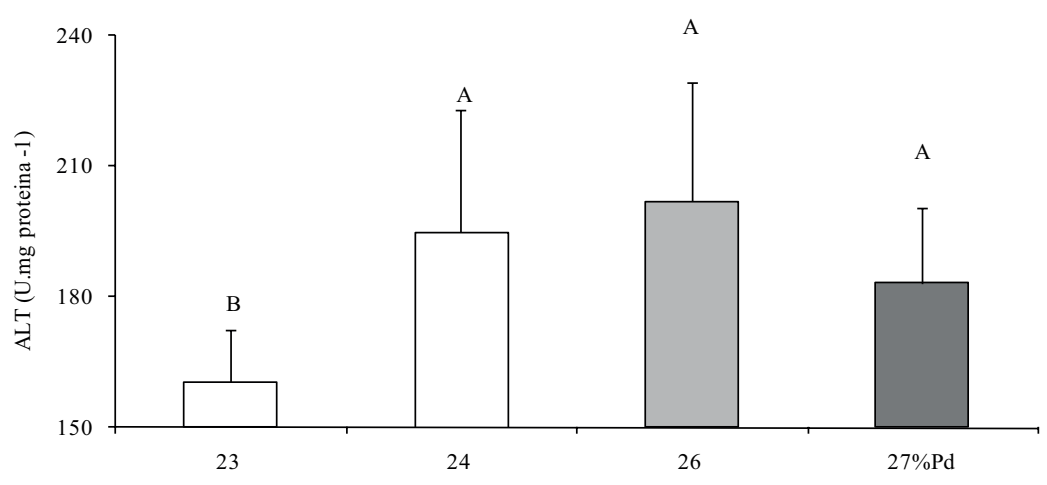

B

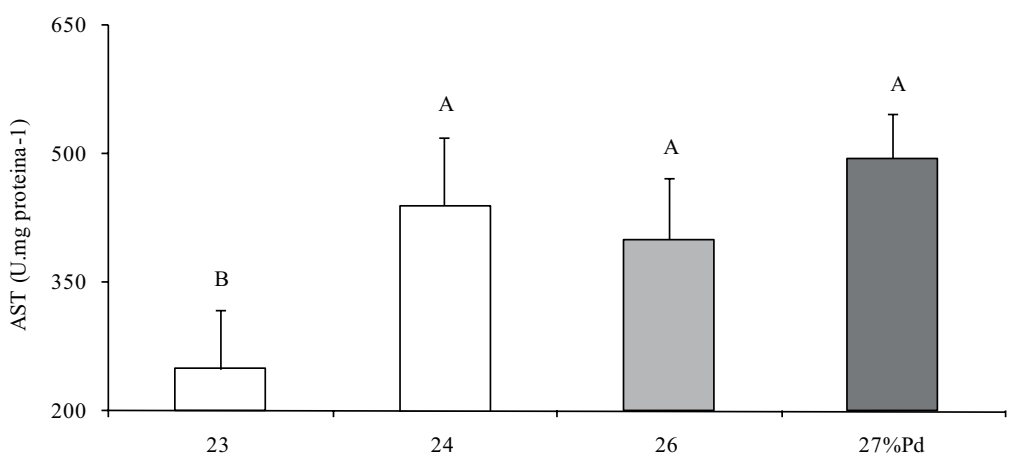

Fonte: Elaboração dos autores.

O intestino anterior do surubim caracterizase por apresentar quatro camadas: a mucosa, a submucosa, a muscular e a serosa. A camada mucosa está constituída por epitélio cilíndrico simples com borda em escova e células caliciformes (PAS positivo), com lâmina própria contendo linfócitos intra-epiteliais; a submucosa formada por células, fibras colágenas e vasos sanguíneos; a camada muscular de músculo liso em disposição circular e externamente à camada serosa, caracterizada por tecido conjuntivo e células pavimentosas (Figura 2A), como também reportado como estrutura 
normal para tilápia do Nilo (HONORATO et al., 2011). A morfometria das vilosidades intestinais não apresentou diferença significativa até o nível de 26\% de proteína digestível (Figura 3A).

Lundstedt (2003) também não observou alteração na altura das vilosidades intestinais de juvenis de surubim quando alimentados com diferentes níveis de proteína. Em controvérsia Honorato et al. (2011) demonstraram correlação positiva entre altura da vilosidade intestinal de tilápia do Nilo, espécie onívora, e o nível de proteína ofertado na dieta.

O fígado do surubim independente do nível de proteína digestível da dieta não apresentou diferença significativa no tamanho dos hepatócitos (Figura 3B) e nenhuma lesão aparente (Figura 4A). A histomorfologia demonstrou distribuição cordonal dos hepatócitos e os sinusóides apresentaram-se revestidos com células endoteliais. Os hepatócitos apresentavam citoplasma claro com núcleo central e formato arredondado e em algumas regiões deslocado para a periferia da célula (Figura 4B). As características morfológicas observadas no fígado dos surubins estão de acordo com as descrições realizadas para outras espécies de peixes neotropicais (FUJIMOTO; CRUZ; MORAES, 2008). Não foi constatada nenhuma alteração referende a sobrecarga no órgão, apesar de que, segundo Seixas Filho et al. (2008) o fígado pode apresentar alterações em sua estrutura pelo excesso de proteína na dieta, devido a sobrecarga do fígado em metabolizar alto nível de proteína ingerida (ALMEIDA et al., 2011). Neste estudo o surubim demonstrou que possui habilidade em metabolizar os níveis de proteína fornecidos.

Figura 2. Foto micrografia de intestino anterior surubins alimentado com dieta $32 \%$ de proteína digestível (A), PAS/H (X 400); células caliciformes (seta) muscular longitudinal (ml), camada muscular interna (mi), membrana serosa $\left({ }^{*}\right)$, epitélio da mucosa (ep), vilosidade intestinal (vi) e enterocito (seta fina).

A

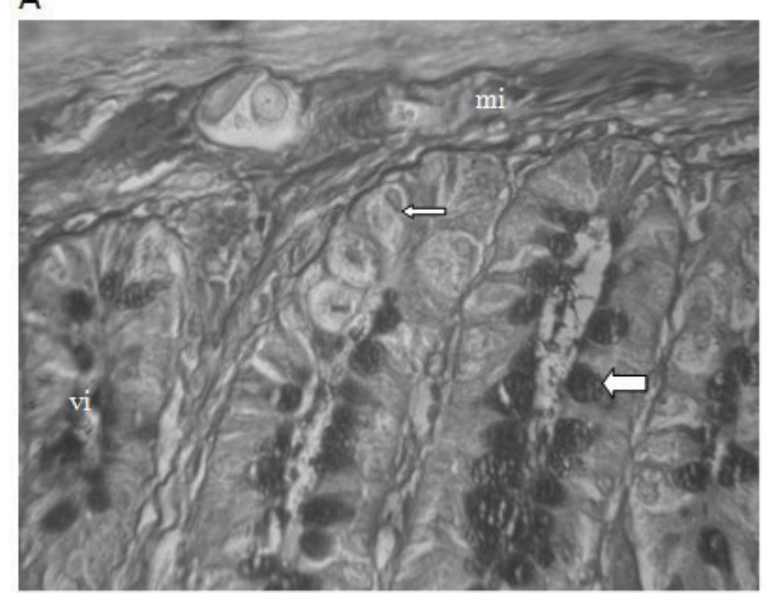

Fonte: Elaboração dos autores.
B

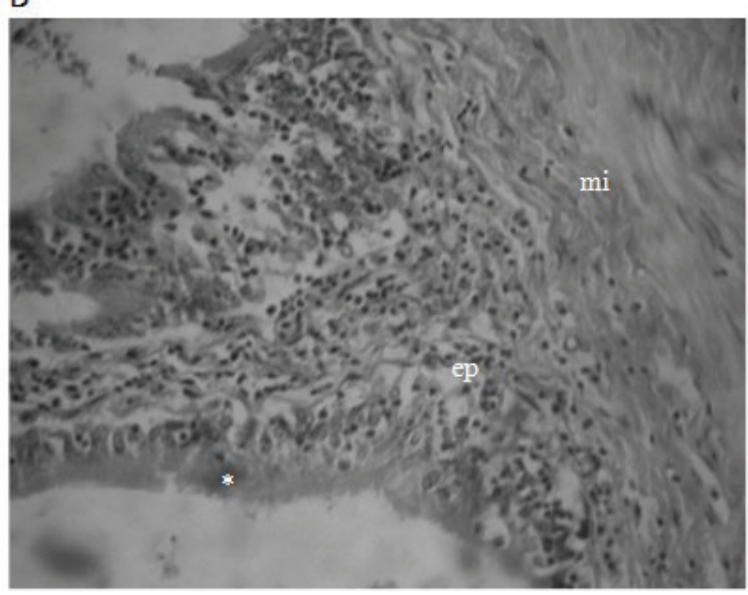


Figura 3. Altura das vilosidades intestinais (A) e área do hepatócitos (B) de surubins submetidos a dietas com níveis crescentes de proteína digestível. Letras distintas reportam diferença estatística pelo teste de Tukey $(\mathrm{p}>0,05)$.

A

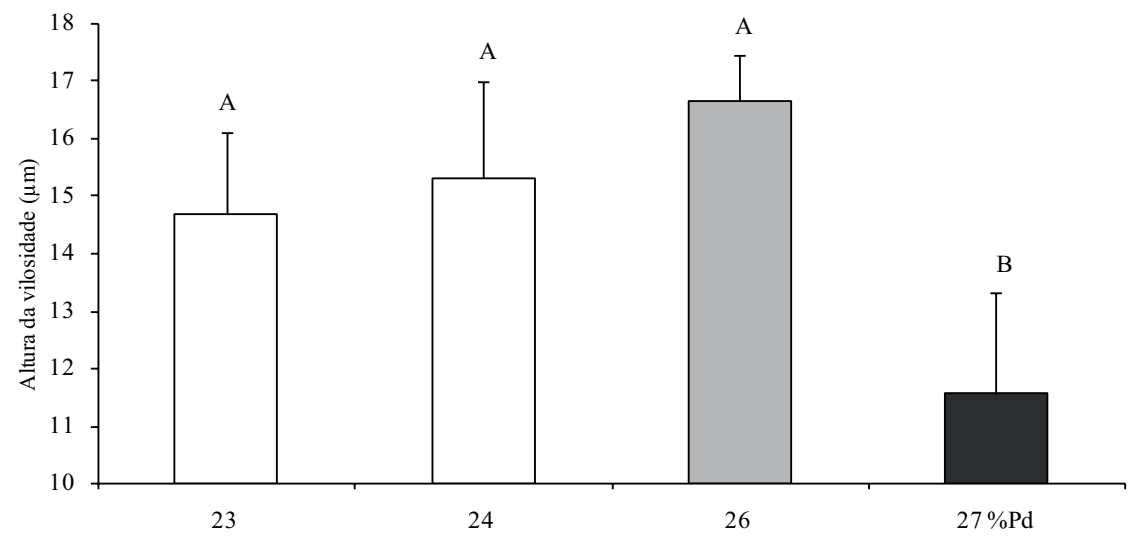

$\mathrm{B}$

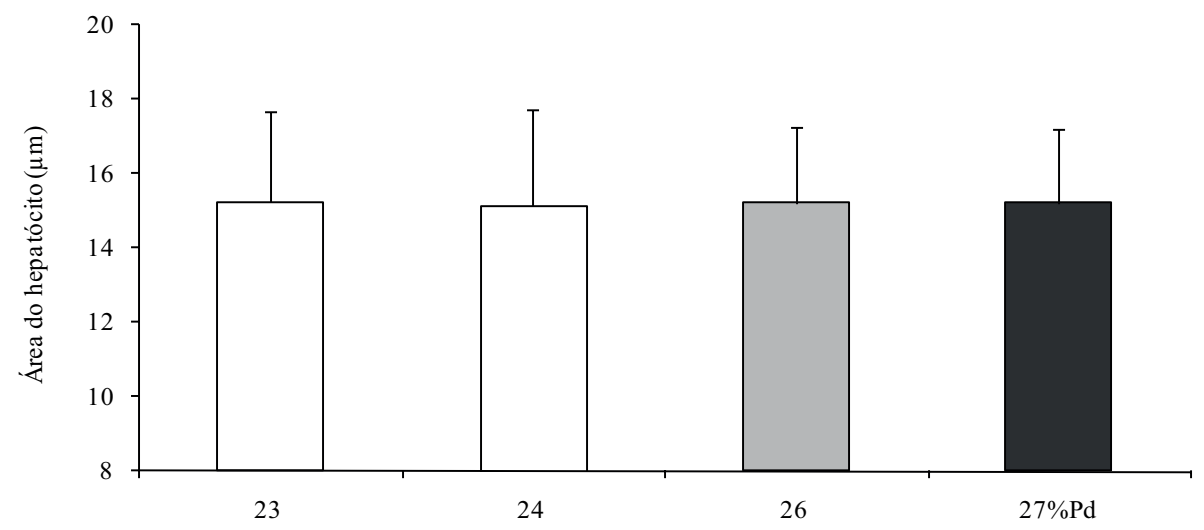

Fonte: Elaboração dos autores.

Figura 4. Foto micrografia do fígado de surubins alimentado com dieta $32 \%$ de proteína digestível (A) PAS/H (X 400) e (B) HE (X 400); hepatócitos arranjo cordonal dos hepatócitos (traço fino).

A

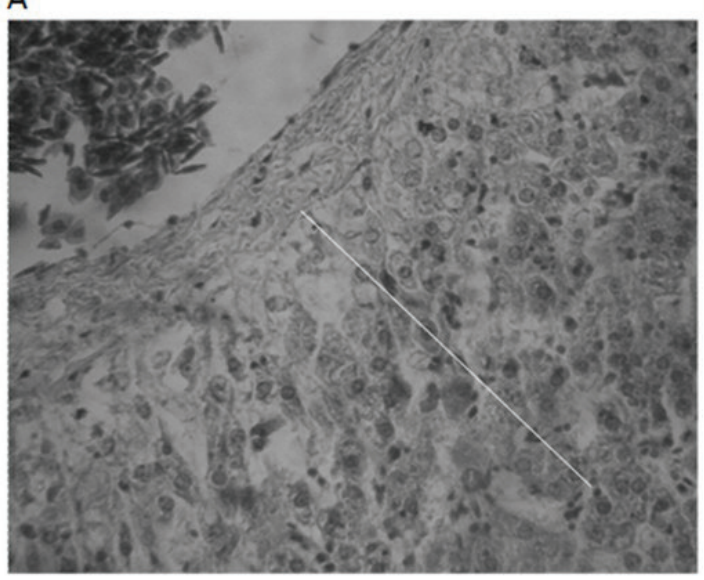

B

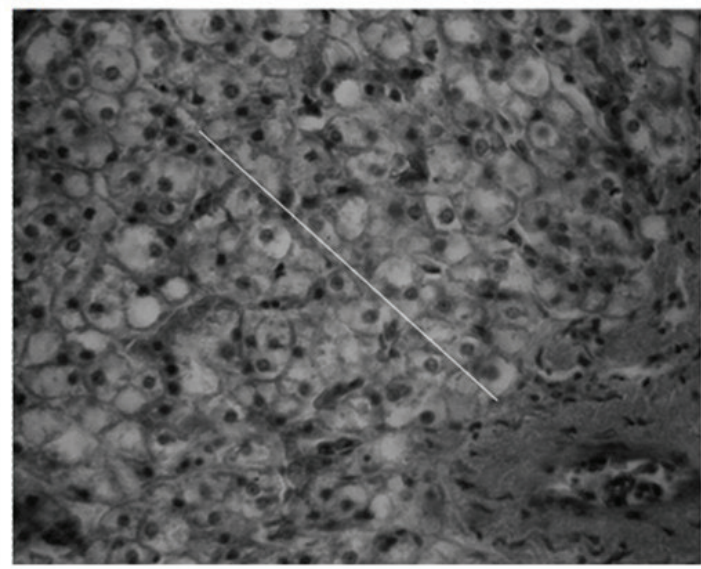

Fonte: Elaboração dos autores. 


\section{Conclusão}

Os juvenis de surubins mostraram-se exigentes em proteína digestível, apresentando os melhores resultados de desempenho de produção e de eficiência de utilização dos nutrientes com uma dieta contendo $28 \%$ de PD.

\section{Agradecimento.}

A empresa Mar \& Terra pelo financiamento e execução do projeto. A Dra. Fernanda P. L. Zauith Diretora do Hospital Veterinário da UNIGRAN.

\section{Referencias}

ALMEIDA FILHO, R. L.; HONORATO, C. A; DE ALMEIDA, L. C.; USHIZIMA, T. T.; SANTAMARIA, F. M. Nutrição de surubim (Pseudoplatystoma sp.) Desafio para aquicultura. Revista Eletrônica Nutritime, Viçosa, v. 9, n. 5, p. 1995-2010, 2012.

ALMEIDA L. C.; AVILEZ, I. M.; HONORATO, C. A.; MORAES, G. Gowth and metabolic responses of tambaqui (Colossoma macropomum) fed diets level of protein and lipid. Aquaculture Nutrition, Oxford, v. 17, n. 2, p. 283-262, 2011.

ASSOCIATION OF OFFICIAL ANALYTICAL CHEMIST - AOAC. Oficial methods of analysis of association official analytical chemists. 17. ed. Arlington: AOAC Inc, v. 1-2, 2000. 1298 p.

AYROZA, L. M. S.; ROMAGOSA, E.; AYROZA, D. M. M. R.; SCORVO FILHO, J. D.; SALLES, F. A. Custos e rentabilidade da produção de juvenis de tilápia-do-Nilo em tanques-rede utilizando-se diferentes densidades de estocagem. Revista Brasileira de Zootecnia, Viçosa, v. 40, n. 2, p. 231-239, 2011.

BICUDO, Á. J. D. A.; BORGHESI, R.; DAIRIKI, J. K.; SADO, R. Y.; CYRINO, J. E. P. Performance of juveniles of Pseudoplatystoma fasciatum fed graded levels of corn gluten meal. Pesquisa Agropecuária Brasileira, Brasília, v. 47, n. 6, p. 838-845, 2012.

BOOTH, M. A.; MOSES, M. D.; ALLAN, G. L.; BOOTH, M. A.; MOSES, M. D.; ALLAN, G. L. Utilisation of carbohydrate by yellowtail kingfish Seriola lalandi. Aquaculture, Amsterdam, v. 376-379, n. 1-4, p. 151-161, 2013.

BURKERT, D.; ANDRADE，D. R.; SIROL，R. N.; SALARO, A. L.; RASGUIDO, J. E. A.; QUIRINO, C. R.
Rendimentos do processamento e composição química de filés de surubim cultivado em tanques-rede. Revista Brasileira de Zootecnia, Viçosa, v. 37, n. 7, p. 11371143, 2008.

CYRINO, J. E. P.; PORTZ, L.; MARTINO, R. C. Retenção de proteína e energia em juvenis de "black bass" Micropterus salmoides. Scientia Agricola, Piracicaba, v. 57, n. 4, p. 609-616, 2000.

DEL CARRATORE, C. R. Desempenho produtivo, digestibilidade e metabolismo energético de juvenis de pintado (Pseudoplatystoma corruscan) alimentados com niveis crescentes de amido. 2001. Tese (Doutorado em Aquicultura) - Centro de Aqüicultura. Universidade Estadual Paulista, Jaboticabal.

FUJIMOTO, R. Y.; CRUZ, C.; MORAES, F. R. Análise de efluente e histologia da pele, fígado e rim de pacus (Piaractus mesopotamicus) suplementados com cromo trivalente. Boletim do Instituto de Pesca, São Paulo, v. 34, n. 1, p. 117-124, 2008.

GONÇALVES, E. G. Coeficientes de digestibilidade aparente da proteina dos alimentos e exigencia de proteina digestivel em dietas para o crescimento do pintado, Pseudoplatystoma coruscans. 2002. Dissertação (Mestrado em Aquicultura) - Centro de Aqüicultura. Universidade Estadual Paulista, Jaboticabal.

GONÇALVES, E. G.; CARNEIRO, D. J. Coeficientes de digestibilidade aparente da proteína e energia de alguns ingredientes utilizados em dietas para o pintado (Pseudoplatystoma coruscans). Revista Brasileira de Zootecnia, Viçosa, v. 32, n. 4, p. 779-786, 2003.

HONORATO, C. A.; ALMEIDA, L. C.; SILVA NUNES, C. da; CARNEIRO, D. J.; MORAES, G. Effects of processing on physical characteristics of diets with distinct levels of carbohydrates and lipids: the outcomes on the growth of pacu (Piaractus mesopotamicus). Aquaculture Nutrition, Oxford, v. 16, n. 1, p. 91-99, 2010.

HONORATO, C. A.; CRUZ, C.; CARNEIRO, D. J.; MACHADO, M. R. F. Histologia e histoquímica do intestino anterior de tilápia do Nilo (Oreochromis niloticus) alimentadas com dietas contendo silagem de peixe. Brazilian Journal Veterinary Research Animal Science, São Paulo, v. 48, n. 4, p. 281-288, 2011.

JIRSA, D.; DENG, D. F.; DAVIS, D. A.; WANG, W. F.; HUNG, S. S. O.; DRAWBRIDGE, M. The effects of dietary lipid levels on performance and heat-shock protein response of juvenile white seabass, Atractoscion nobilis. Aquaculture Nutrition, Oxford, v. 19, n. 2, p. 227-232, 2013.

LIRANÇO, A. D. S.; ROMAGOSA, E.; SCORVOFILHO,J.D. Desempenho produtivo de Pseudoplatystoma 
corruscans estocados em sistemas de criação: semiintensivo (viveiro escavado) e intensivo (tanque-rede). Ciência Rural, Santa Maria, v. 41, n. 3, p. 524-530, 2011.

LUNDSTEDT, L. M.; MELO, J. F. B.; MORAES, G. Digestive enzymes and metabolic profile of Pseudoplatystoma corruscans (Teleostei: Siluriformes) in response to diet composition. Comparative Biochemistry and Physiology, Amsterdam, v. 137B, n. 3, p. 331-339, 2004.

LUNDSTEDT, L. M. Aspectos adaptativos dos processos digestivo e metabólico de juvenis de pintado (Pseudoplatystoma corruscans) arraçoados com diferentes níveis de proteína e energia. 2003. Tese (Doutorado em Genética e Evolução) - Universidade Federal de São Carlos, São Carlos.

MARTINO, R. C.; CYRINO, J. E. P.; PORTZ, L.; TRUGO, L. C. Performance and fatty acid composition of surubim (Pseudoplatystoma coruscans) fed diets with animal and plant lipids. Aquaculture, Amsterdam, v. 209, n. 1-4, p. 233-246, 2002.

MELO, J. F. B.; LUNDSTEDT, L. M.; METO, N. I.; BAANANTE, I. V.; MORAES, G. Effects of dietary levels of protein on nitrogenous metabolism of Rhamdia queen (Teleostei: Pimelodidae). Comparative Biochemistry and Physiology - Part A: Molecular \& Integrative Physiology, Amsterdam, v. 145A, n. 2, p. 181-187, 2006.

METÓN, I.; MEDIAVILLA, D.; CASERAS, A.; CANTÓ, E.; FERNÁNDEZ, F.; BAANATE, I. V. Effect of diet composition and ratio size on key enzymes activity of glycolysis-gluconeoenesis, the pentose phosphate pathway and amino acid metabolism in liver of gilthead sea bream (Sparus aurata). British Journal of Nutrition, Cambridge, v. 82, n. 1, p. 223-232, 1999.

ONO, E. A. Criação de peixes em tanques-rede. In: ZOOTEC, 2005, Campo Grande. Anais... Campo Grande: ZOOTEC, 2005. p. 1-14.
REITMAN, S.; FRANKEL, S. A colorimetric method for determination of serum glutamic oxaloacetic and glutamic pyruvic transaminase. American Journal of Clinical Pathology, Chicago, v. 28, n. 56, p. 53-63, 1957.

RESENDE, S. R.; CAVALCANTE, J. L.; MELO, J. P. H.; PADUA, D. M. C. Desenvolvimento do surubim surubim, Pseudoplatystoma corruscans em tanque-rede de pequeno volume. In: SOCIEDADE BRASILEIRA DE ZOOTECNIA, 44., 2007, Jaboticabal. Anais... Jaboticabal: UNESP, 2007. p. 1-3.

SAMPAIO, F. G.; LOSEKANN, M. E.; LUIZ, A. J. B.; NEVES, M. C.; FRASCÁ-SCORVO, C. M. D.; RODRIGUES, G. S. Monitoramento e gestão ambiental da piscicultura em tanques-rede em reservatórios. Informe Agropecuário, Belo Horizonte, v. 34, n. 272, p. $1-11,2013$.

SÁNCHEZ-MUROS， M. J.; GÁRCIA-REJÓN， L.; GÁRCIA-SALGUERO, L.; LA HIGUERA, M.; LUPIÁÑES, J. A. Long-term nutritional effects on the primary liver and kidney metabolism in raimbow trout. Adaptive response to starvation and high-protein, carbohydrate-free diet on glutamate dehydrogenase and alanine aminotransferase kinetics. Biochemistry and Cell Biology, Ottawa, v. 30, n. 1, p. 55-63, 1998.

SEIXAS FILHO, J. T.; HIPOLITO, M.; CARVALHO, V. F.; MARTINS, A. M. C. R. P. F.; SILVA, L. N.; CASTAGNA, A. A. Alterações histopatológicas em girinos de rã-touro alimentados com rações comerciais de diferentes níveis protéicos. Revista Brasileira de Zootecnia, Viçosa, v. 37, n. 12, p. 2085-2089, 2008.

ZANARDI, M. F.; BOQUEMBUZO, J. E.; KOBERSTEIN, T. C. R. Desempenho de juvenis de pintado (Pseudoplatystoma coruscans) alimentados com três diferentes dietas. Revista Acadêmica de Ciências Agrárias e Ambientais, Curitiba, v. 6, n. 4, p. 445-450, 2008 . 
